\title{
SALUD
}

\section{Vulneración del derecho a la salud en la prisión}

\author{
José Galeano Monti , Oscar Balbuena Jara
}

\section{Resumen}

Objetivo: Este trabajo tiene como principal objetivo llevar a cabo un análisis y descripción acerca del grado de acceso a servicios de salud de la población privada libertad, adulta y adolescente, varones y mujeres; específicamente en cárceles y centros educativos del Paraguay.

Material y Método: Se analizaron los datos sociodemográficos, y tres ejes, de dos investigaciones llevadas a cabo por el MNP: (i) el acceso a servicios relacionados a la salud en la prisión; (ii) el acceso a la salud por parte de personas adultas en cárceles, y de adolescentes en centros educativos para adolescentes en conflicto con la ley; y, (iii) la situación de la salud sexual y reproductiva en cárceles y centros educativos del Paraguay. La metodología escogida para llevar a cabo el análisis fue la de 'análisis de datos secundarios' (Vieytes, 2004).

Resultados y Conclusión: Los datos indican que el acceso al agua, a los servicios de salud, y a la educación sexual están vulnerados por las políticas de salud de las instituciones estudiadas; además, según los datos, no existe atención las 24 horas en las sanidades, y no se tienen en cuenta las necesidades reales de las poblaciones, principalmente las más vulnerables, que se encuentran privada de libertad. Los datos arrojados por las investigaciones analizadas, indican que las personas privadas de libertad son, en su mayoría, varones, y provienen de zonas urbanas en la mayoría de los casos; asimismo, se pudo observar a través de los datos que adolescentes, tanto mujeres como varones, así como mujeres y varones adultos, fueron vulnerados en el derecho a la educación previamente a su encierro.

Las cárceles no garantizan el acceso al derecho a contar con agua potable, ya que en varias cárceles se observó la precariedad de este servicio en los contextos de encierro. No se tiene acceso continuado a agua potable para beber, así como tampoco higiene, ni para saneamiento de los espacios en donde viven.

En las cárceles del Paraguay no se garantiza el acceso a alimentación adecuada, necesaria y digna, en el sentido de calidad de la comida; así como tampoco se garantiza un correcto régimen alimentario para personas con necesidades específicas y en condiciones particulares de vulnerabilidad, como adolescentes y personas adultas (de 60-65 años y más), lo que pone en serio riesgo la salud de estas.

Acerca del acceso a los servicios de salud en las cárceles, toda la evidencia científica indica que no se cuenta con personal médico capacitado en la medida

1. Mecanismo Nacional de Prevención de la Tortura (MNP), Paraguay.

E-mail: jose.galeano@mnp.gov.py

DOI: 10.26885/rcei.foro.2017.155 
de lo necesario; además, los horarios no cubren 24 horas al día.

Igualmente, los datos dan cuenta de que en las cárceles y los centros educativos existen sistemas paralelos de poder montados por guardias, celadores y educadores, que exigen el pago, ya sea con dinero o bienes, para abrirles los portones y así poder ir a consultar a la sanidad. Esta situación en gran medida coarta las posibilidades de las personas, principalmente aquellas que no tienen dinero ni bienes, de acceder a los lugares en donde las instituciones ofrecen los servicios de salud.

Las instituciones tampoco tienen en cuenta las necesidades reales de las poblaciones estudiadas; asimismo se pudo observar que existen sistemas de poder paralelos a los de las cárceles, la cuales dificultan el acceso a los servicios de salud.

Con relación a la salud mental, se halló que los servicios existentes en las cárceles no están realmente dirigidos a los procesos de reinserción social y económica de las personas privadas de libertad, sino que existen y son utilizados únicamente como sistemas obligados desde el marco legal y jurídico; y la mayoría de las consultas se realizan obligadas por parte de los y las internas, y no como un sistema que colabore con la reinserción de las mismas.

El sistema de acceso a controles ginecológicos no está garantizado. Los mismos son necesarios para las mujeres como método de prevención de enfermedades como el cáncer y que las ciencias médicas recomiendan realizarse según rangos de edad específicamente definidos, sin embargo estos estudios no se les realiza a todas las mujeres privadas de libertad; en el mismo sentido, tampoco todas las mujeres que sí pudieron acceder a ellos tuvieron oportunidad de recibir los resultados del estudio, denotando además un déficit en la retroalimentación en la relación médico-paciente.

Los varones mayores (de 60-65 años y más) no tienen garantizado el derecho al acceso a controles médicos específicos que guardan relación con el sexo y la edad, como lo describe la falta de acceso a controles de próstata, los cuales se recomiendan realizar a edades avanzadas.

Las mujeres embarazadas no tienen acceso a insumos necesarios para sus hijos; igualmente, los y las niñas que viven en las cárceles con sus madres tampoco tienen garantizado el acceso a atenciones pediátricas en las instituciones de encierro, tampoco tienen políticas de salud relacionadas a madres en cárceles que permitan llevar a los y las niñas a ser atendidas fuera de las cárceles.

Las persona privadas en general no cuentan con conocimientos básicos sobre planificación familiar, métodos anticonceptivos, ni infecciones de transmisión sexual (ITS). En las instituciones de encierro no se cuenta con políticas de educación sexual para las personas que están privadas de libertad, no se les instruye siquiera en el uso adecuado del condón, como para evitar el contagio de enfermedades de transmisión sexual; tampoco se les educa en el conocimiento y uso de otros métodos de anticoncepción, como para contar con la capacidad de planificar la cantidad de hijos que desea tener. 
Palabras clave: salud, cárceles, centros educativos, adolescentes, personas adultas, tortura, derechos.

\section{RefERENCIAS}

Mecanismo Nacional de Prevención de la Tortura (MNP). (2015). Censo de mujeres privadas de libertad 2015. Condiciones de vida, vulneración de derechos humanos, tortura y malos tratos. Asunción: MNP.

Mecanismo Nacional de Prevención de la Tortura (MNP). (sf). Derecho a la salud en ámbitos de intervención del MNP, ¿garantía o vulneración? Asunción: MNP.

Paraguay. Ley N² 4288/2011. Del Mecanismo Nacional de Prevención de la Tortura y otros Tratos o Penas Crueles, Inhumanas o Degradantes.

Vieytes, R. (2004). Metodología de la investigación en organizaciones, mercado y sociedad. Epistemología y técnicas. Buenos Aires: de las ciencias. 